\title{
Wer auf Antibiotika nicht anspricht, hat wohl keine Neuroborreliose
}

\author{
Unspezifische Symptome, kein Liquorbefund, deutliche \\ Residualsymptome nach einer Therapie - bei solchen Patienten \\ liegt mit hoher Wahrscheinlichkeit kein Borrelieninfekt vor. \\ Experten warnen daher von einer Langzeitantibiose.
}

_ „Es hat auch schon Todesfälle gegeben", kommentierte Prof. Dr. Sebastian Rauer vom Uniklinikum Freiburg auf dem Kongress der Deutschen Gesellschaft für Neurologie (DGN) in Mannheim die langfristige Gabe von Antibiotika bei Patienten mit vermeintlicher Neuroborreliose. Er warnte daher eindringlich vor einer Behandlung über Monate oder gar Jahre hinweg. Rauer verwies auf systematische Reviews, nach denen bei einer früh erkannten und rechtzeitig behandelten Neuroborreliose von einer sehr guten Prognose auszugehen sei. Dafür genüge eine zwei- bis dreiwöchige Behandlung. „Eine längere oder intensivere Antibiotikatherapie bringt keinen Zusatznutzen, sondern setzt die Patienten aufgrund der Nebenwirkungen einem unnötigen Risiko aus“, so der Neuroborreliose-Spezialist.

\footnotetext{
Kein Liquorbefund - mehr Residualsymptome nach der Therapie Noch immer jedoch würden Patienten mit Borrelioseverdacht aufgrund von unspezifischen Beschwerden wie chronische Erschöpfung, zumeist degenerativ bedingte Gelenkschmerzen, Kopfschmerzen, Antriebsstörungen oder Missempfindungen über einen längeren Zeitraum mit Antibiotika traktiert Rauer verwies dabei auf unspezifische Verfahren wie den Leukozyten-Transformationstest oder den Nachweis von Serumantikörpern, die eine aktive Borreliose belegen sollen. „80\% der Borrelieninfekte verlaufen inapparent. Der Nachweis von Antikörpern im Serum bringt daher nichts.“ Der Spezialist er-
}

innerte daran, dass nur bei einem positiven Liquorbefund in Kombination mit typischen klinischen Symptomen eine Neuroborreliose wahrscheinlich ist. "Ohne erhöhte Zellzahl im Liquor und ohne intrathekale Borrelien-spezifische Antikörper geht die Wahrscheinlichkeit für eine Neuroborreliose gegen Null.“

Entsprechend wenig Erfolg sei bei solchen Patienten auch von einer Antibiose zu erwarten. Der Neurologe verwies auf eine Cochrane-Analyse mit über 1.300 Patienten, von denen rund die Hälfte nur eine „mögliche Neuroborreliose“ hatte - bei ihnen war der Liquor nicht untersucht worden. Solche Patienten hatten deutlich häufiger unspezifische Beschwerden, auch war die Therapie

„Der Nachweis
von Anti-
körpern im
Serum bringt
nichts."
weit weniger erfolgreich als bei Betroffenen mit einer liquordiagnostisch bestätigten Borreliose. Diese sprachen in der Regel recht gut auf die Behandlung an und zeigten anschließend deutlich seltener Residualsymptome als die Patienten ohne Liquorbefunde (24 versus $31 \%)$.

„Der häufigste Grund für den mangelnden Erfolg einer Antibiokatherapie ist wohl eine Fehldiagnose“, sagte Rauer.

\section{Schmerzlinderung begünstigt Antibiotika-Langzeittherapie}

Viele Patienten und auch einige Ärzte schwören dennoch auf eine langfristige Behandlung. Dies erklärte der Spezialist zum Teil mit den antiphlogistischen Efdeln." konferenz. fekten der meisten Antibiotika. „Den Patienten geht es zunächst tatsächlich besser. Das verstärkt die Überzeugung, versteckte Borrelien im Körper zu haben. Wird das Antibiotikum abgesetzt, lassen der antiphlogistische Effekt und die Placebowirkung nach." Am Ende stehe eine Dauerbehandlung, die den Betroffenen schade.

Um solche Fehldiagnosen und Fehlbehandlungen zu vermeiden, setzt die DGN zusammen mit anderen Fachgesellschaften, aber auch mit „Gruppierungen, die eine Borreliose ganz anders sehen", auf eine S3-Leitlinie, erläuterte Rauer. Bisher existiert für die Neuroborreliose nur eine Experteneinschätzung auf $\mathrm{S} 1-\mathrm{Ni}$ veau.

Die neue Leitlinie soll Anfang des kommenden Jahres veröffentlicht werden. Derzeit würde intensiv die Literatur nach evidenzbasierten Aussagen durchforstet. Zwei Ergebnisse wollte der Experte bereits nennen: Zum einen scheint eine orale Therapie mit Doxycyclin ähnlich gut zu wirken wie eine I.v.-Behandlung mit Betalaktamen, zum anderen genügen zwei bis drei Wochen für die Behandlung. „Die Studien sind hier sehr eindeutig: Es macht keinen Unterschied, ob Sie 20 oder 100 Tage behan-

\section{Thomas Müller}

- 89. Kon2gress der Deutschen Gesellschaft für Neurologie (DGN), Mannheim, 21.-24. September 2016. Fachpresse- 